\title{
Postoperative Speech Outcomes and Complications in Submucous Cleft Palate Patients
}

\author{
Tae Seo Park ${ }^{1}$, Yong Chan Bae ${ }^{1,2}$, Su Bong Nam ${ }^{1}$, Kyung Dong Kang ${ }^{1}$, Ji Yoon Sung ${ }^{1}$ \\ ${ }^{I}$ Department of Plastic and Reconstructive Surgery, Pusan National University School of Medicine, Busan; ${ }^{2}$ Biomedical Research Institute, \\ Pusan National University Hospital, Busan, Korea
}

Background The postoperative speech outcomes of submucous cleft palate (SMCP) surgery are known to be poorer than those of other types of cleft palate. We attempted to objectively characterize the postoperative complications and speech outcomes of the surgical treatment of SMCP through a comparison with the outcomes of incomplete cleft palate (ICP).

Methods This study included 53 SMCP patients and 285 ICP patients who underwent surgical repair from 1998 to 2015. The average age of the patients at the time of surgery was $3.9 \pm 1.9$ years for the SMCP patients and $1.3 \pm 0.9$ years for the ICP patients. A retrospective analysis was performed of the complications, the frequency of subsequent surgical correction for velopharyngeal dysfunction (VPD), and speech outcomes.

Results In both the SMCP and ICP patients, no cases of respiratory difficulty, bleeding, or wound disruption were noted. Delayed wound healing and fistula occurred in 18.9\% and $5.7 \%$ of the SMCP patients and in 14\% and $3.2 \%$ of the ICP patients, respectively. However, no statistically significant difference in either delayed wound healing or fistula occurrence was observed between the two groups. The rate of surgical correction for VPD in the SMCP group was higher than in the ICP group. In the subset of 26 SMCP patients and 62 ICP patients who underwent speech evaluation, the median speech score value was 58.8 in the SMCP group and 66 in the ICP group, which was a statistically significant difference.

Conclusions SMCP and ICP were found to have similar complication rates, but SMCP had significantly worse speech outcomes.

Keywords Cleft palate / Speech / Velopharyngeal insufficiency
Correspondence: Yong Chan Bae Department of Plastic and Reconstructive Surgery, Pusan National University School of Medicine, Biomedical Research Institute, Pusan National University Hospital, 179 Gudeok-ro, Seo-gu, Busan 49241, Korea Tel: +82-51-240-7273 Fax: +82-51-243-9405 E-mail: baeyc2@hanmail.net

This work was supported by a clinical research grant from Pusan National University Hospital in 2016.

This article was presented at the 73rd Congress of the Korean Society of Plastic and Reconstructive Surgeons on November 13-15, 2015 in Seoul, Korea.

No potential conflict of interest relevant to this article was reported.

Received: 9 Nov 2015 • Revised: 11 Feb 2016 • Accepted: 18 Feb 2016

pISSN: 2234-6163 • elSSN: 2234-6171 • http://dx.doi.org/10.5999/aps.2016.43.3.254 • Arch Plast Surg 2016;43:254-257

\section{INTRODUCTION}

The early surgical correction of cleft palate generally leads to favorable postoperative speech outcomes. However, submucous cleft palate (SMCP) is often asymptomatic and thus is characterized by delays in diagnosis. Once diagnosed, physicians typically keep patients with this condition under regular follow-up observation, often for long periods of time, before surgical treatment is needed, and thus SMCP tends to be treated surgically later than other types of cleft palate.

The surgical treatment of SMCP is not effective in improving speech performance. The reason for its poor effectiveness has not been conclusively determined, but is probably due to delays in surgical treatment. 
In order to objectively evaluate speech performance outcomes and the incidence of complications after the surgical treatment of SMCP, we compared the outcomes of SMCP patients with those of incomplete cleft palate (ICP) patients.

\section{METHODS}

\section{Subjects}

Fifty-three SMCP patients and 285 ICP patients, all of whom were nonsyndromic and aged less than ten years, underwent surgical correction in the plastic surgery department of our institution between January 1998 and April 2015 and were included in our study. The SMCP group included 27 males and $26 \mathrm{fe}-$ males, ranging in age from 10 months to eight years (mean \pm standard deviation $[\mathrm{SD}], 3.9 \pm 1.9$ years) at the time of surgery. The ICP group included 94 males and 191 females, ranging in age from seven months to six years (mean $\pm \mathrm{SD}, 1.3 \pm 0.9$ years) at the time of surgery (Table 1). All operations were performed by a single surgeon. The most frequent type of surgery was the Busan modification [1] in both groups, followed by double opposing Z-plasty in the SMCP group and two-flap palatoplasty in the ICP group (Table 2).

\section{Methods}

The subjects' medical records were retrospectively analyzed, and information was extracted regarding the occurrence of postoperative complications, the frequency of additional surgical corrections for velopharyngeal dysfunction (VPD), and speech evaluation scores.

\section{Complications}

Complications were categorized as respiratory difficulty, bleeding, wound disruptions, delayed wound healing (defined as requiring at least two weeks longer than anticipated or involving superficial ulceration), and oronasal fistula.

\section{Velopharyngeal dysfunction correction}

We determined how many patients underwent surgical correction for sustained symptoms of VPD despite speech therapy during the postsurgical observation period.

\section{Table 1. Distribution of type of cleft palate, sex, and age}

\begin{tabular}{|lrrrr|}
\hline $\begin{array}{l}\text { Type of cleft } \\
\text { palate }\end{array}$ & Male & Female & Total & $\begin{array}{c}\text { Mean age at operation } \\
\text { (yr) }\end{array}$ \\
\hline Submucous & 27 & 26 & 53 & $3.9 \pm 1.9$ (range, 0.8-8) \\
Incomplete & 94 & 191 & 285 & $1.3 \pm 0.9$ (range, 0.6-6) \\
\hline
\end{tabular}

\section{Speech articulation test}

A subset of 26 SMCP patients and 62 ICP patients who could be observed postoperatively and were four or more years of age underwent speech evaluation. On average, speech evaluation was performed 1.7 years postoperatively for the SMCP patients and 3.6 years postoperatively for the ICP patients. The Simple Speech Screening Protocol for Korean Cleft Palate Patients by Kim et al. [2] in 1999 was used to score their speech. This scale contains a total of 22 items about hypernasality (5), plosives (7), fricatives (2), affricates (3), laterals (2), and nasals (3), as well as one item that is scored as 1 for severe hypernasality or articulation difficulties, 2 for moderate hypernasality or articulation difficulties, and 3 for normal articulation. The highest possible score is 66 . Five plastic surgeons and five medical students trained in the evaluation guidelines evaluated the subjects' speech using this scale.

Fisher's exact test was used to determine between-group differences in the likelihood of additional VPD correction and complications, and the Mann-Whitney U test was used to evaluate between-group differences in the speech evaluation scores. P-values $<0.05$ were considered to indicate statistical significance, and all statistical analyses were performed using SPSS ver. 22.0 (IBM Co., Armonk, NY, USA).

\section{RESULTS}

While respiratory difficulty, bleeding, and wound disruption were not observed in any subjects, the SMCP group was slightly more likely to experience complications than the ICP group, with incidence rates of delayed wound healing of $18.9 \%$ and $14 \%$, respectively, and incidence rates of fistula of $5.7 \%$ and $3.2 \%$, respectively (Table 3). However, these differences were not statistically significant.

Additional surgical correction was performed for VPD in nine SMCP patients (17\%) and seven ICP patients (2.5\%). The SM$\mathrm{CP}$ group was significantly more likely to require VPD correction than the ICP group $(\mathrm{P}<0.001)$.

Table 2. Surgical techniques used to treat cases of submucous and incomplete cleft palate

\begin{tabular}{|lcc|}
\hline Surgical technique & Submucous & Incomplete \\
\hline Busan modification & $28(53)$ & $158(55.4)$ \\
Two-flap palatoplasty & $3(5.6)$ & $106(37.1)$ \\
Double opposing Z-plasty & $19(35.8)$ & $14(5)$ \\
Intravelar veloplasty & $3(5.6)$ & $7(2.5)$ \\
Total & $53(100)$ & $285(100)$ \\
\hline Values are presented as number (\%). & \\
\hline
\end{tabular}


Table 3. Postoperative complications following primary cleft palate surgery

\begin{tabular}{|lccc|}
\hline $\begin{array}{l}\text { Type of } \\
\text { complication }\end{array}$ & $\begin{array}{c}\text { Submucous } \\
\text { cleft palate } \\
\text { (53 patients) }\end{array}$ & $\begin{array}{c}\text { Incomplete } \\
\text { cleft palate } \\
\text { (285 patients) }\end{array}$ & P-value \\
\hline Respiratory difficulty & 0 & 0 & - \\
Bleeding & 0 & 0 & - \\
Wound disruption & 0 & 0 & - \\
Delayed wound healing & $10(18.9)$ & $40(14)$ & 0.399 \\
Fistula & $3(5.7)$ & $9(3.2)$ & 0.411 \\
Total & $13(24.6)$ & $49(17.2)$ & - \\
\hline $\begin{array}{l}\text { Values are presented as number (\%). } \\
\text { alFisher's exact test. }\end{array}$ & & \\
\hline
\end{tabular}

On the postoperative speech evaluation, the $26 \mathrm{SMCP}$ patients received scores ranging from 35 to 66 (median, 58.8), and the scores of the 62 ICP patients ranged from 27 to 66 (median, 66) (Table 4). The SMCP group had poorer speech outcomes than the ICP group $(\mathrm{P}=0.002)$.

\section{DISCUSSION}

The incidence rate of postoperative palatal fistula has been reported to range from $0 \%$ to $45 \%$. Emory et al. [3] found that the rate depended on the experience of the surgeons, while Ahmed et al. [4] found that it depended on the severity of the cleft, as classified by the Veau system: $0 \%(0 / 15)$ for Veau class I clefts, $12 \%$ (6/50) for class II clefts, $22.22 \%$ (12/54) for class III clefts, and $45.45 \%$ (5/11) for class IV clefts.

In patients with SMCP, Sullivan et al. [5] reported that the incidence rate of postoperative fistula was 7\% (1/15) for Z-plasty, Seagle et al. [6] found that it was 6\% (1/18) for Furlow palatoplasty, and Abyholm [7] reported that it was 5\% (1/19) for Von Langenbeck palatoplasty.

In this study, the incidence of postoperative fistula was found to be $3.2 \%$ in the ICP group and 5.7\% in the SMCP group, which were similar to the incidence rates reported by previous studies. Although the incidence of fistula was higher in the SMCP group than in the ICP group, no statistically significant difference was observed between the two groups.

Kaplan [8] suggested that the best time for palate repair is three to six months after birth, and Dorf and Curtin [9] reported that surgery at approximately the age of one year can have a significant effect on speech abnormalities. Given these age-related outcomes, early palatal closure can lead to good postoperative results. Some researchers insist that similarly to overt cleft palate, SMCP should be surgically treated before the language development period. Pensler and Bauer [10] argued that surgery should be performed before the age of two years. Chung et al.
Table 4. Postoperative speech outcomes using the Simple Speech Screening Protocol

\begin{tabular}{|c|c|c|c|}
\hline & $\begin{array}{c}\text { Submucous cleft } \\
\text { palate } \\
\text { (26 patients) }\end{array}$ & $\begin{array}{c}\text { Incomplete cleft } \\
\text { palate } \\
\text { (62 patients) }\end{array}$ & P-value ${ }^{a)}$ \\
\hline Speech score & $58.8(35-66)$ & 66 (27-66) & 0.002 \\
\hline
\end{tabular}

[11] contended that early surgical treatment can correct and prevent VPD, because the skeletal structure, which determines the position of the nasopharynx as well as that of the soft tissues, can be an anatomical cause of VPD. In contrast, McWilliams [12] reported that $44 \%$ of SMCP patients had no specific symptoms until they reached adulthood, and Weatherley-White et al. [13] found that $90 \%$ of SMCP patients did not require early surgical treatment. Since some patients with SMCP may have no speech disorders, it is widely accepted that surgical correction should be considered when symptoms of velopharyngeal incompetence are found, during the period from the first diagnosis of VPD until the age of three or four years.

Although conditions such as muscular diastasis were taken into account, the SMCP patients received surgical treatment if they showed speech problems after a certain period of time. Consequently, in this study, the average age of the SMCP patients at the time of surgery was $3.9 \pm 1.9$ years, which was older than the average age of the ICP patients $(1.3 \pm 0.9$ years $)$. The median speech score value of the SMCP group after surgery was 58.8 (range, 35-66), which was lower than the score of 66 (range, 27-66) of the ICP group. Furthermore, 17\% of the SMCP group received additional correction due to VPD sustained after surgery, which was overwhelmingly greater than the $2.5 \%$ of the ICP group; therefore, the delayed time of surgery may be considered to be the cause of the relatively poor language development observed in the SMCP group.

However, Park et al. [14] reported that the postoperative results of SMCP repair were not significantly affected by age. In our experience, SMCP often manifests as extremely thin mucous membranes, scant submucosal tissue, and poor development of the levator muscle. Thus, in our study, differences in the anatomical structure between the groups can also be considered one of the causes of the poor speech performance observed in the SMCP group.

Ideally, further research should be conducted that strictly controls for the variables of age, surgical method, and operating surgeon in order to definitively identify the causes of poor speech performance in patients treated for SMCP. In Korea, a country with high accessibility to healthcare and a well-functioning sys- 
tem of prenatal diagnosis, the majority of cleft palate patients visit the hospital in the early stage of the condition. Currently, however, the generally accepted guideline is to decide upon surgery after follow-up observation of the occurrence of problems in feeding, otology, or speech, which might, on average, result in later treatment for SMCP patients than for ICP patients. Performing surgery in SMCP patients in the early stage of their condition simply in order to compare them with ICP patients would be ethically questionable. Given this reality, we conducted a study restricted to patients less than 10 years of age in order to overcome these limitations in the study design as much as possible.

The strengths of this study are also worth noting; namely, a single surgeon performed operations in two relatively large groups and reviewed the results using an objective metric.

In conclusion, although the incidence rate of complications was slightly higher in the SMCP group than in the ICP group, no statistically significant difference was observed. SMCP was more likely to require additional VPD correction and was associated with poorer postoperative speech outcomes than ICP.

\section{REFERENCES}

1. Bae YC, Lee JW, Seo HJ. Modified palatoplasty method (Busan modification) for incomplete type cleft palate. J Craniofac Surg 2015;26:1203-6.

2. Kim JH, Bae YC, Hwang SM, et al. simple method of speech evaluation in the Korean patient with cleft palate. J Korean Soc Plast Reconstr Surg 1999;26:858-65.

3. Emory RE Jr, Clay RP, Bite U, et al. Fistula formation and repair after palatal closure: an institutional perspective. Plast Reconstr Surg 1997;99:1535-8.

4. Ahmed MK, Maganzini AL, Marantz PR, et al. Risk of per- sistent palatal fistula in patients with cleft palate. JAMA Facial Plast Surg 2015; 17:126-30.

5. Sullivan SR, Vasudavan S, Marrinan EM, et al. Submucous cleft palate and velopharyngeal insufficiency: comparison of speech outcomes using three operative techniques by one surgeon. Cleft Palate Craniofac J 2011;48:561-70.

6. Seagle MB, Patti CS, Williams WN, et al. Submucous cleft palate: a 10-year series. Ann Plast Surg 1999;42:142-8.

7. Abyholm FE. Submucous cleft palate. Scand J Plast Reconstr Surg 1976;10:209-12.

8. Kaplan EN. Soft palate repair by levator muscle reconstruction and a buccal mucosal flap. Plast Reconstr Surg 1975;56: 129-36.

9. Dorf DS, Curtin JW. Early cleft palate repair and speech outcome. Plast Reconstr Surg 1982;70:74-81.

10. Pensler JM, Bauer BS. Levator repositioning and palatal lengthening for submucous clefts. Plast Reconstr Surg 1988;82: 765-9.

11. Chung JH, Lee SH, Park BY, et al. Study of cranial base structure and velopharyngeal movement in patients with submucous cleft palate using velopharyngogram. J Korean Soc Plast Reconstr Surg 1998;25:1328-37.

12. McWilliams BJ. Submucous clefts of the palate: how likely are they to be symptomatic? Cleft Palate Craniofac J 1991; 28:247-9.

13. Weatherley-White RC, Sakura CY Jr, Brenner LD, et al. Submucous cleft palate: its incidence, natural history, and indications for treatment. Plast Reconstr Surg 1972;49:297-304.

14. Park S, Saso Y, Ito O, et al. A retrospective study of speech development in patients with submucous cleft palate treated by four operations. Scand J Plast Reconstr Surg Hand Surg 2000;34:131-6. 